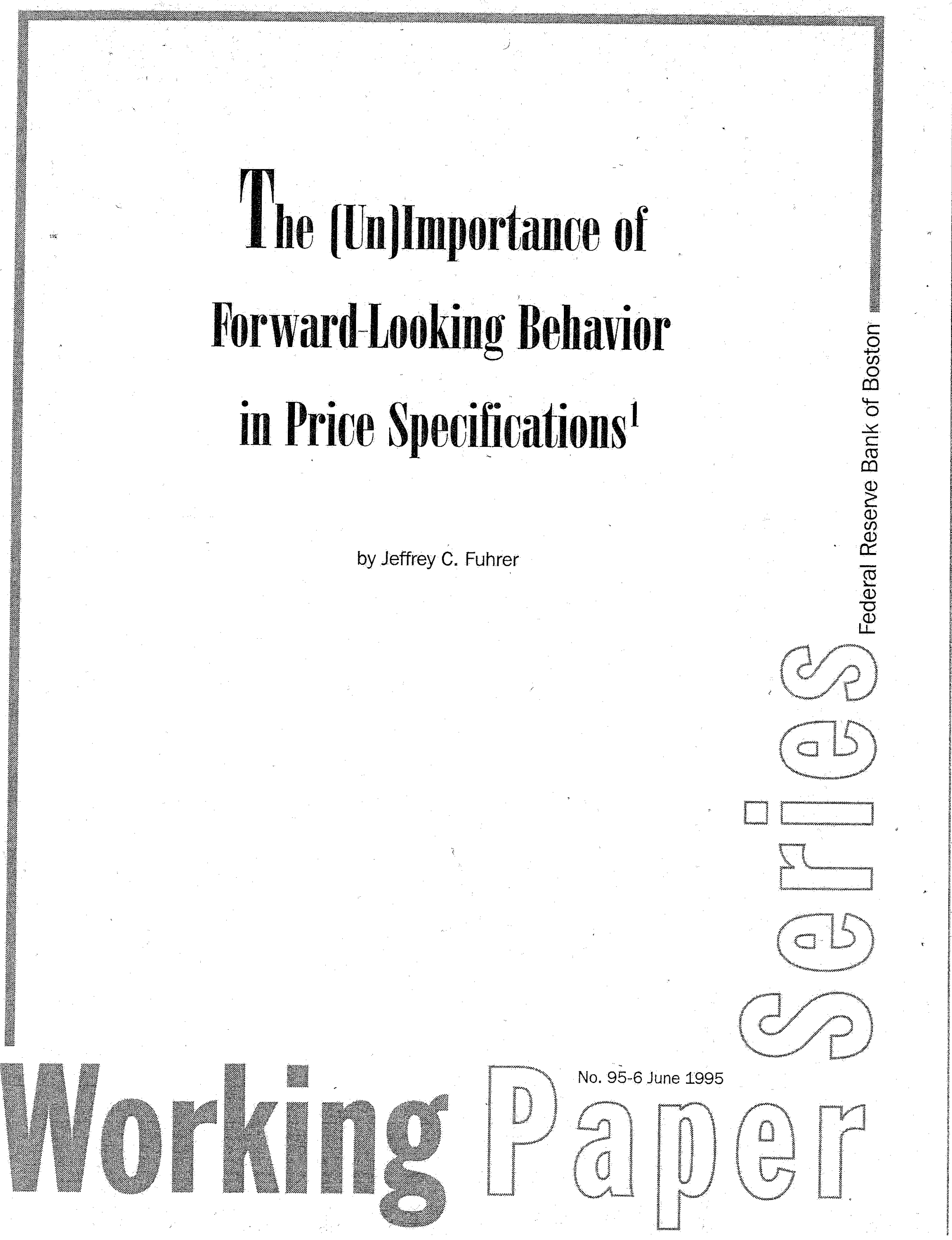




\section{The (In)Importance of \\ ForwardLLoking Behavior in Price Specifications}

by Jeffrey $C$. Fuhrer

June 1995

Working Paper No. 95-6

Federal Reserve Bank of Boston 


\title{
The (Un)Importance of Forward-Looking Behavior in Price Specifications ${ }^{1}$
}

\author{
Jeffrey C. Fuhrer \\ Federal Reserve Bank of Boston
}

June 8, 1995

PRELIMINARY DRAFT

Comments Welcome

\begin{abstract}
The seminal work of Phelps, Taylor, and Calvo developed forwardlooking models of price determination that imparted inertia to the price level. These models incorporate expectations of future prices and excess demand by imposing constraints (typically lag-lead symmetry constraints) that force future variables to enter the specification. In this paper, I test the empirical significance of future prices in specifications like those of Taylor. I find that expectations of future prices are empirically unimportant in explaining price and inflation behavior. However, the dynamics of a model that includes a purely backwardlooking inflation specification differ significantly-and not altogether pleasingly-from those with a forward-looking specification.
\end{abstract}

\footnotetext{
${ }^{1}$ I thank Alicia Sasser for excellent research assistance. The views expressed in this paper are those of the author and do not necessarily reflect positions of the Federal Reserve Bank of Boston or the Federal Reserve System.
} 
Some of the earliest and best-known macroeconomic models that impose rational expectations are the models of Sargent and Wallace (1975). These models were widely criticized for implying that prices were completely flexible and cleared markets instantaneously. The implication of price flexibility appeared to conflict markedly with empirical observations of measures of the aggregate price level. Initially, some confusion arose as to whether the assumption of rational expectations inherently entailed price flexibility. However, the work of Taylor (1980) and others demonstrated the critical point that it was the price specification, not the assumption of rational expectations, that led to the unlikely price behavior in the early models. Significant and realistic inertia could be imparted to prices in a rational expectations macro model.

Yet the inclusion of expectations in the price sector of Taylor's and others' models arises through a set of constraints that essentially force expectations to enter the specification. Of course, some restrictions are necessary in order to separately identify the effects of expected future variables. If the model is specified with unconstrained leads and lags, it will be difficult for the data to distinguish between the leads, which solve out as restricted combinations of lag variables, and unrestricted lags. In most cases, these constraints take the form of symmetry restrictions across past and expected future prices.

This paper attempts to test the importance of the expected prices in explaining price fluctuations by relaxing these restrictions. The paper uses a variety of inflation specifications that are derived from the standard contracting models of Taylor (1980) and from a new contracting specification that more accurately mimics the inertia in observed inflation rates, drawing on the work of Phelps (1978), Ball (1991), Chadha, Masson and Meredith (1992), and Fuhrer and Moore (1995, [9] and [10]).

In addition, the paper explores the consequences of forward-looking, backward- 
looking, and mixed price specifications for the overall dynamic behavior of a macro model. To anticipate, I find that, consistent with others, the purely foward-looking price model bears implications that are severely at odds with the data. In addition, the mixed backward-looking/forward-looking model implies considerably different model dynamics from a purely backward-looking model. I will argue that the purely backward-looking model's dynamics are less plausible than the mixed model, although this conclusion may be somewhat model-specific, and depends somewhat upon prior beliefs.

\section{The Analytics of the Price Models}

Consider three types of price specifications. The first, which I will call an expectations-augmented price-price Phillips curve, sets the current inflation rate, $\pi_{t}$ equal to the expected inflation rate, $\pi_{t}^{e}$, adjusted for excess demand, $\tilde{y}_{t}$.

$$
\pi_{t}=\pi_{t+1}^{e}+\gamma \tilde{y}_{t}
$$

In the usual implementation of the expectations-augmented Phillips curve, expected inflation is proxied by a distributed lag on past inflation. ${ }^{2}$ Thus equation 1 may be written

$$
\pi_{t}=\sum_{i=0}^{k} \beta_{i} \pi_{t-i}+\gamma \tilde{y}_{t}
$$

where $\sum \beta_{i}=1$ in order to satisfy the "natural rate" hypothesis of Lucas (1972). This equation has properties that one would expect: when policymakers pursue a disinflation $\left(\tilde{y}_{t}<0\right)$, inflation decreases over time.

It is useful to contrast this behavior with the behavior of a discrete-time

\footnotetext{
${ }^{2}$ See, for example, Brayton and Mauskopf (1985) for a description of the MIT-PENNSSRC (MPS) model.
} 
version of the Calvo (1983) model, which is nearly identical to a two-period Taylor (1980) overlapping contracts model. In both cases, inflation follows the process

$$
\pi_{t}=E_{t} \pi_{t+1}+\gamma \tilde{y}_{t}
$$

The differences here are twofold. First, as pointed out in Chadha, Masson, and Meredith (1992) and Fuhrer and Moore (1992), the inflation rate is independent of lagged inflation, depending only on expected inflation, and is thus completely flexible. Second, the response of inflation to a contraction in excess demand $\left(\tilde{y}_{t}<0\right)$ is contrary to intuition. For negative $\tilde{y}_{t}$, the expected change in inflation must be positive. When aggregate demand is contractionary, inflation is expected to rise. The only way it can do so and still deflate (and attain its new equilibrium value) is to jump down and rise to its new, lower, equilibrium from below. These dynamics stand at odds with the disinflation experiences of the United States and a host of other countries; see Ball (1994) for documentation.

Finally, consider the model developed in Fuhrer and Moore (1995, [9]), which extends the Taylor staggered contracting framework in a way that imparts persistence to the rate of inflation. That model is shown to be equivalent to a two-sided Phillips curve with the same sort of symmetry restrictions imposed in the Taylor model on wages and wage contracts:

$$
\pi_{t}=f(L) f\left(L^{-1}\right)\left[\pi_{t}+\gamma g^{-1}(L) \tilde{y}_{t}\right]
$$

where $f(L)=f_{0}+f_{1} L+f_{2} L^{2} \ldots$ is the lag polynomial that describes the distribution of price contracts in the model; $f_{i}$ is the fraction of price contracts negotiated in period $t-i$ that are still in effect in period $t$. A two-period version of this model shows the sensible inflation dynamics inherent in the 
specification:

$$
\begin{aligned}
\pi_{t} & =(1 / 2)\left[\pi_{t-1}+E_{t} \pi_{t+1}\right]+\gamma \tilde{y}_{t} \\
E_{t} \Delta \pi_{t+1}-\Delta \pi_{t} & =-\gamma \tilde{y}_{t}
\end{aligned}
$$

Here, when monetary policy pursues a contractionary disinflation, the expected change in inflation must increase, while the rate of inflation falls, as expected, in accordance with equation 3 . Inflation falls at a decreasing rate towards its new, lower, equilibrium.

The specifications summarized in equations 2 and 3 include expected prices (or inflation rates) by imposing symmetry restrictions across lags and leads that arise from the underlying contracting specifications. The next section relaxes those restrictions and attempts to determine the importance of expected prices in explaining price and inflation movements.

\section{How Important Are Expectations in the Inflation Specifications?}

A simple specification that nests the purely forward-looking, the two-sided, and the backward-looking inflation equations is ${ }^{3}$

$$
\pi_{t}=\mu\left[\frac{1}{3}\left(\pi_{t-1}+\pi_{t-2}+\pi_{t-3}\right)\right]+(1-\mu)\left[\frac{1}{3} E_{t}\left(\pi_{t+1}+\pi_{t+2}+\pi_{t+3}\right)\right]+\gamma \tilde{y}_{t}
$$

where the parameter $\mu$ indexes the weight on the past relative to expectations of the future, and $E_{t}$ denotes the rational expectation conditioned on the information set available at time $t$. In equation $1, \mu=1$; in equation 3 ,

\footnotetext{
${ }^{3}$ Chadha, Masson, and Meredith (1992) explore the implications of a similar specification.
} 
$\mu=\frac{1}{2}$.

For a four period Taylor specification, the lag/lead pattern in terms of inflation is a bit more complicated. Ignoring expectations, the inflation equation that is consistent with the Taylor contracting specification is: ${ }^{4}$

$$
\pi_{t}-\pi_{t+1}=-\frac{1}{6} \pi_{t-2}-\frac{1}{2} \pi_{t-2}+\frac{1}{2} \pi_{t+2}+\frac{1}{6} \pi_{t+3}+\frac{2}{3} \gamma \tilde{y}_{t}
$$

where $\dot{y}_{t}$ is an equally-weighted moving average of the excess demand term $y_{t}$. The Taylor specification implies restrictions on the leads and lags of inflation; however, they are not symmetric as in the other specifications. ${ }^{5}$

\subsection{Estimates of the Weight on Expected versus Lagged Inflation}

The first test for forward-looking behavior in prices estimates equation 4 via maximum likelihood, using vector autoregressive equations for $\tilde{y}$ and the federal furds rate. The last is included because it has been shown to be an important predictor of real activity by a number of authors, including Bernanke and Blinder (1992). ${ }^{6}$ The data employed are described in Table 1. The sample for this initial estimation is 1966:I-1994:I.

The VAR equations for the output gap and the nominal interest rate include four lags each of inflation, the output gap, and the interest rate.

\footnotetext{
${ }^{4}$ This equation is derived directly from the Taylor (1980) model. Using $n=4$ and dropping the expectations operator for simplicity, substitute the equation for the contract wage $x_{t}=\sum_{i} p_{t+i}+\gamma y_{t}$ into the definition of the price index $p_{t}=\sum_{i} x_{t-i}$, then re-express the resulting price equation in terms of inflation rates.

${ }^{5}$ The pattern of coefficients in this inflation equation appears somewhat counterintuitive: last period's positive inflation rates exert a negative influence on current inflation. While the vector autoregressive solution to the forward-looking equation will have different coefficients on lagged inflation, the behavior implied by the structural equation is perverse. See Fuhrer and Moore (1995a) for more details on the behavior of this specification.

${ }^{6}$ The method of estimation is described fully in Fuhrer and Moore (1995a).
} 
Table 1

Quarterly Data, 1966Q1-1994Q1

\begin{tabular}{cl}
\hline Mnemonic & Definition \\
\hline$y_{t}$ & $\log$ of per capita \$82 GDP \\
$p_{t}$ & log of the implicit GDP deflator \\
$f_{t}$ & Quarterly federal funds rate \\
$\pi_{t}$ & Inflation rate, $4 \Delta p_{t}$ \\
$\tilde{y}_{t}$ & Deviation of $y_{t}$ from trend
\end{tabular}


The estimated equation is

$$
\pi_{t}=\underset{(.14)}{.96}\left[\frac{1}{3}\left(\pi_{t-1}+\pi_{t-2}+\pi_{t-3}\right)\right]+\underset{(-)}{.04}\left[\frac{1}{3} E_{t}\left(\pi_{t+1}+\pi_{t+2}+\pi_{t+3}\right)\right]+\underset{(.04)}{.13} \dot{\tilde{y}}_{t}
$$

where asymptotic standard errors are reported in parentheses below the estimates. The data seem to be consistent with very little weight on expected future inflation, consistent with but somewhat more lopsided than the results in Chadha et al. (1992).

We cannot reject the hypothesis that price-setters place zero weight on the expected future, $\mu=1$. The estimated value of $\gamma$ under this hypothesis is .14 with a standard error of .04 . The likelihood ratio test statistic for this hypothesis takes the value .01 with $p$-value .92 . The hypothesis that $\mu=.5$, as in the Fuhrer-Moore model, can be weakly rejected with a $p$ value of .098 . The hypothesis that inflation depends only on expected future values of inflation $(\mu=0)$ is overwhelmingly rejected, with a likelihood ratio statistic of 230 and a $p$-value of essentially zero.

Of course, only in the simplest two-period Taylor model would we expect inflation to be purely forward-looking. As equation 5 shows, a four-period version of the Taylor contracting model implies dependence on past inflation as well. However, this specification does not imply a symmetric lag/lead pattern, and so it is of interest to estimated less restricted lag/lead versions of equation 4. An unconstrained inflation equation that nests the Taylor inflation model is

$$
\pi_{t}=\sum_{i=1}^{2} \alpha_{i} \pi_{t-i}+\sum_{j=1}^{3} \beta_{j} E_{t} \pi_{t+j}+\gamma \tilde{y}_{t}
$$

where the sum constraint $\sum_{i} \alpha+\sum_{j} \beta_{j}=1$ is imposed. Estimating this model 
yields coefficients of

$$
\begin{aligned}
& \pi_{t}=.44 \pi_{t-2}+.38 \pi_{t-1}-.09 E_{t} \pi_{t+1} \\
& \begin{array}{lll}
(.28) \quad(.14) \quad(.57)
\end{array} \\
& -.71 E_{t} \pi_{t+2}+.97 \quad E_{t} \pi_{t+3}+.02 \tilde{y}_{t}
\end{aligned}
$$

None of the individual expected future values are estimated to be insignificantly different from zero. The likelihood ratio test for the hypothesis that all leads are jointly zero fails to reject with $p$-value .53. Thus the expected future inflation values are inessential from the perspective of the Taylor (asymmetric lag/lead) model as well.

For these data series, for these specifications, and under the assumption of rational expectations, it is difficult to argue that the expectations of future inflation play an important role in explaining current inflation. In essence, this says that if we assume that price-setters used inflation expectations that are roughly consistent with the historical interactions among inflation, real output, and interest rates, those expectations were not important inputs to price decisions.

\subsection{Have Expectations Recently Become More Im- portant?}

Performing the same exercise over the post-nonborrowed reserves operating procedure period (post-1982:QIV), I find that the qualitative conclusions are unchanged. I re-estimate the vector autoregressive equations for real output and the furds rate, and conditioned on these, re-estimate $\mu$ and $\gamma$ for the 
more recent sample period. Interestingly, the point estimate for $\mu$ falls from .96 to .57 , suggesting additional weight on inflation expectations. But once again, the likelihood ratio test for the hypothesis that the inflation equation is backward-looking, $\mu=1$, takes the value 1.08 with $p$-value 0.3 . Thus the data cannot reject the hypothesis that price-setters are purely backwardlooking, even in the more recent sample.

\section{Other Implications of Backward- and Forward- Looking Inflation Models}

The evidence presented above suggests that the data clearly favor a partly backward-looking specification over a purely forward-looking inflation specification. However, the evidence also suggests that the data cannot distinguish with any confidence between a purely backward-looking specification and a mixed specification, as long as the mix is not weighted too heavily on the future.

When the data cannot distinguish among different specifications, economists often turn to prior beliefs to distinguish among competing specifications. In this section, I argue that my prior beliefs about the dynamic interactions among inflation, real output, and interest rates in the macroeconomy lead me to favor a forward-looking inflation specification over a purely backwardlooking one. It may be possible that the desirable features that I find in a forward-looking price model can be replicated by other modifications to the specification. Thus, my arguments point to the importance of forwardlooking behavior as a sufficient, but certainly not necessary, condition for dynamic behavior that conforms to my priors.

I will examine two simple graphical representations of the dynamic behavior of the price specifications. The first is the vector autocorrelation function 
implied by the specifications. The second is a revealing simulation exercise.

\subsection{A Snapshot of the Model's Dynamics}

Figure 1 presents the vector autocorrelation functions (VACF) for three specifications. The first is the VACF for an unconstrained vector autoregression in inflation, the output gap, and the federal funds rate. The second is the VACF for the $\mu=.5$ specification, and the last is the VACF for the purely backward-looking specification $(\mu=1)$. As the figure indicates, the differences among the VACFs are significant.

The most important difference between the VAR and $\mu=.5$ specifications and the $\mu=1$ specifications is that the $\mu=1$ specification's auto- and cross-correlations die out much more slowly. While the dominant roots for the systems differ only modestly -.95 for the VAR and the $\mu=.5$ model versus .98 for the $\mu=1$ model-the implications for dynamic behavior are substantial. In part, this is due simply to the miracle of compounding: For a model with a .95 root, a unit shock is reduced by $80 \%$ after 32 quarters; the same shock to a model with a .98 root has decayed only $50 \%$ after 32 quarters. To decay $80 \%$ takes 80 quarters for the .98 root process; at which point the .95 root process has essentially decayed to 0 .

While one could certainly not distinguish statistically between a .95 and a .98 root, the economic implications of the two can be significantly different. To highlight the differences, I present several simulations that show the response of the models to shocks. 
Figure 1

\section{Comparison of Vector Autocorrelation Functions \\ VAR \\ $\mu=1$ \\ $\mu=.5---$}
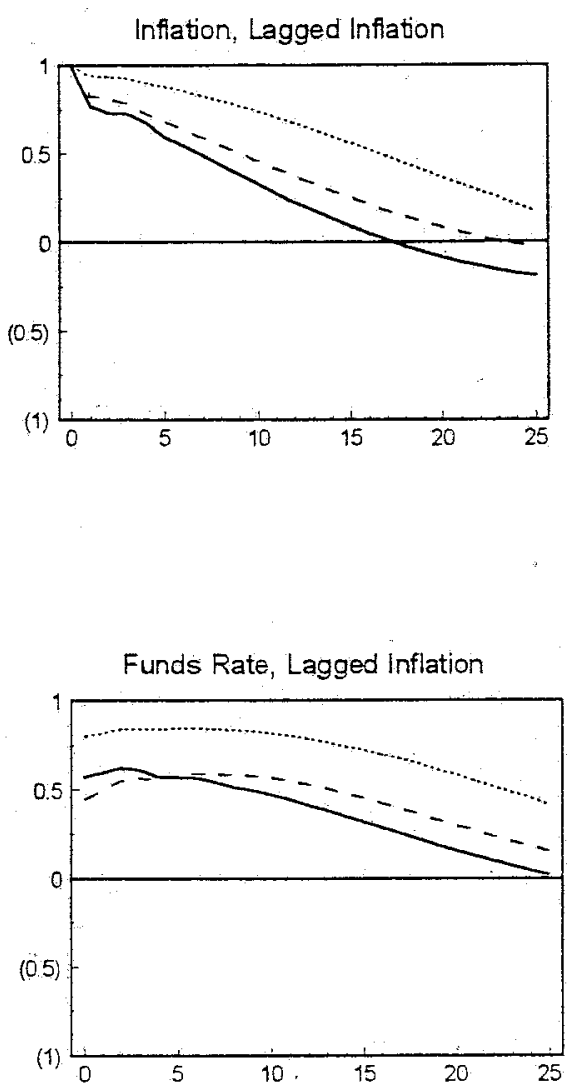

Output, Lagged Infiation

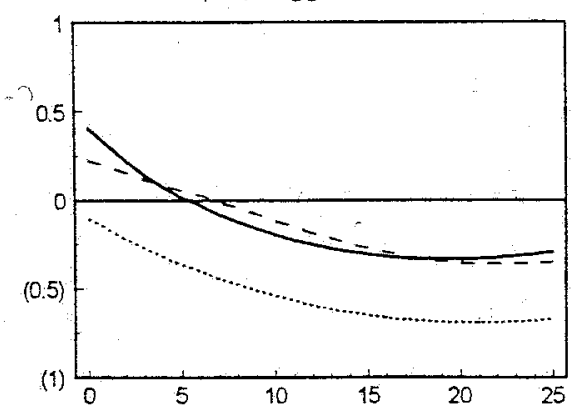

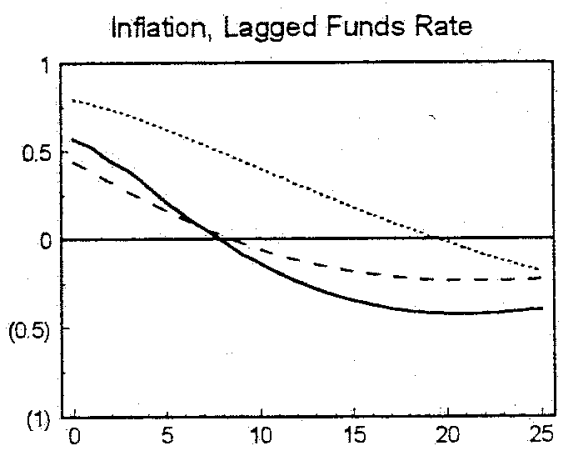

Funds Rate, Lagged Funds Rate

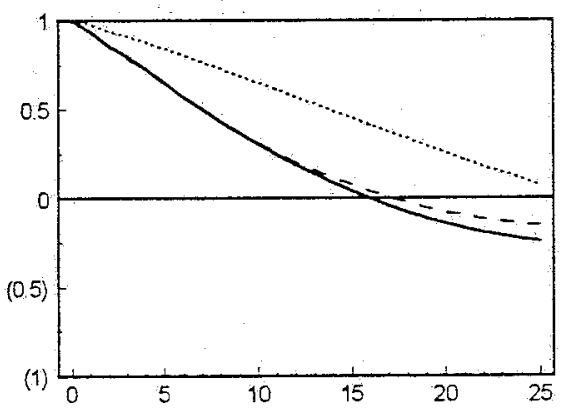

Output, Lagged Funds Rate

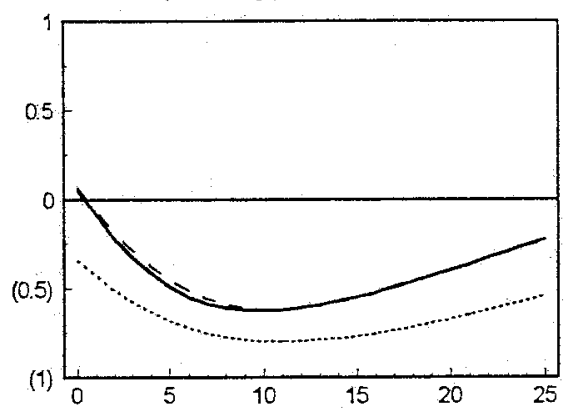

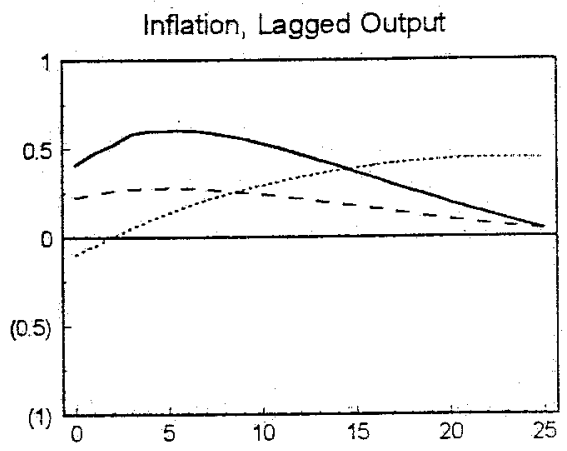

Funds Rate, Lagged Output

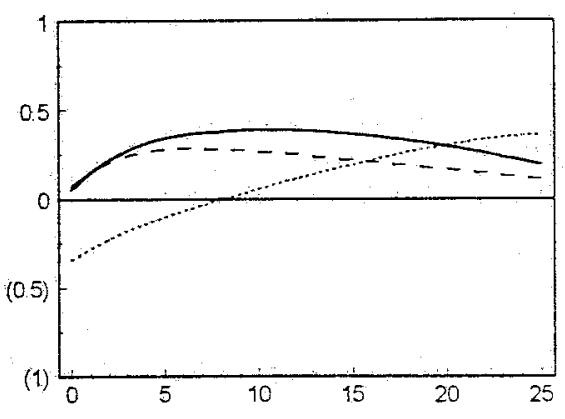

Output, Lagged Output

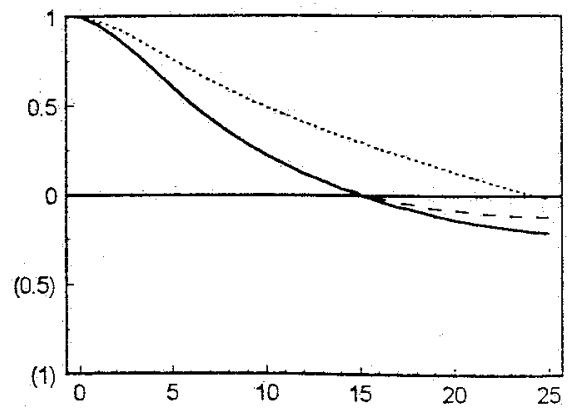




\subsection{The Behavioral Differences between Backward- Looking and Mixed Models}

Figures 2 and 3 depict the response of the output gap and inflation to a 1 percentage point decrease in the implicit inflation target. ${ }^{7}$ These simulations can be thought of as disinflations, although the monetary policy reaction function is not explicitly modeled.

The obvious difference between the two models is that the backwardlooking model implies implausibly long and vigorous responses to events many years ago. It seems implausible that the output gap twenty years after a disinflation would still be responding significantly, if at all, to the initial tightening that brings about the disinflation. In the dashed lines in Figures 2 and 3 , beginning from a steady state, the output gap drops initially by .8 percent, then peaks at +.5 percent twenty years later.

The solid lines provide a striking contrast. The output gap falls by about as much as in the backward-looking case, but output returns to potential and essentially remains there for the rest of the simulation. Similarly, inflation drops from its initial steady-state of $3 \%$ to $2 \%$ within a few years and essentially stays there for the remainder of the simulation. While one could quibble about the precise contours and the magnitudes of the responses in either model, what stands out is the qualitative difference between the models.

I suggest that the qualitative behavior of the model with some forwardlooking price behavior conforms better to most economists' priors than the behavior of the model that is purely backward-looking. Most economists would feel uncomfortable predicting that a shock to the inflation target would have significant effects on real output twenty to forty years later. While there

\footnotetext{
${ }^{7}$ The inflation target is implicit in the VAR equation for the funds rate.
} 
Figure 2

\section{Comparison of Inflation Models During a Disinflation}

Output Gap

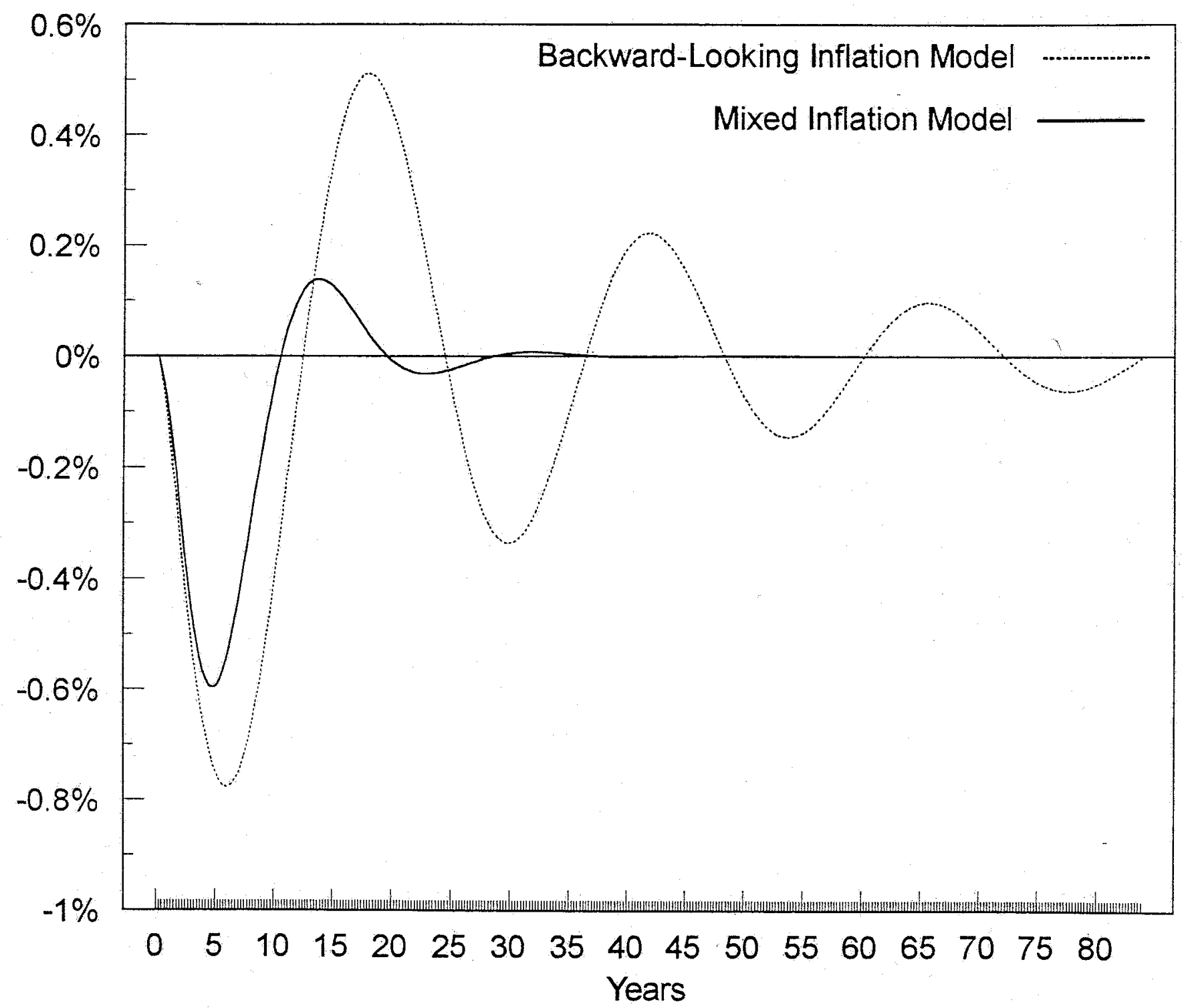


Figure 3

\section{Comparison of Inflation Models \\ During a Disinflation}

Inflation

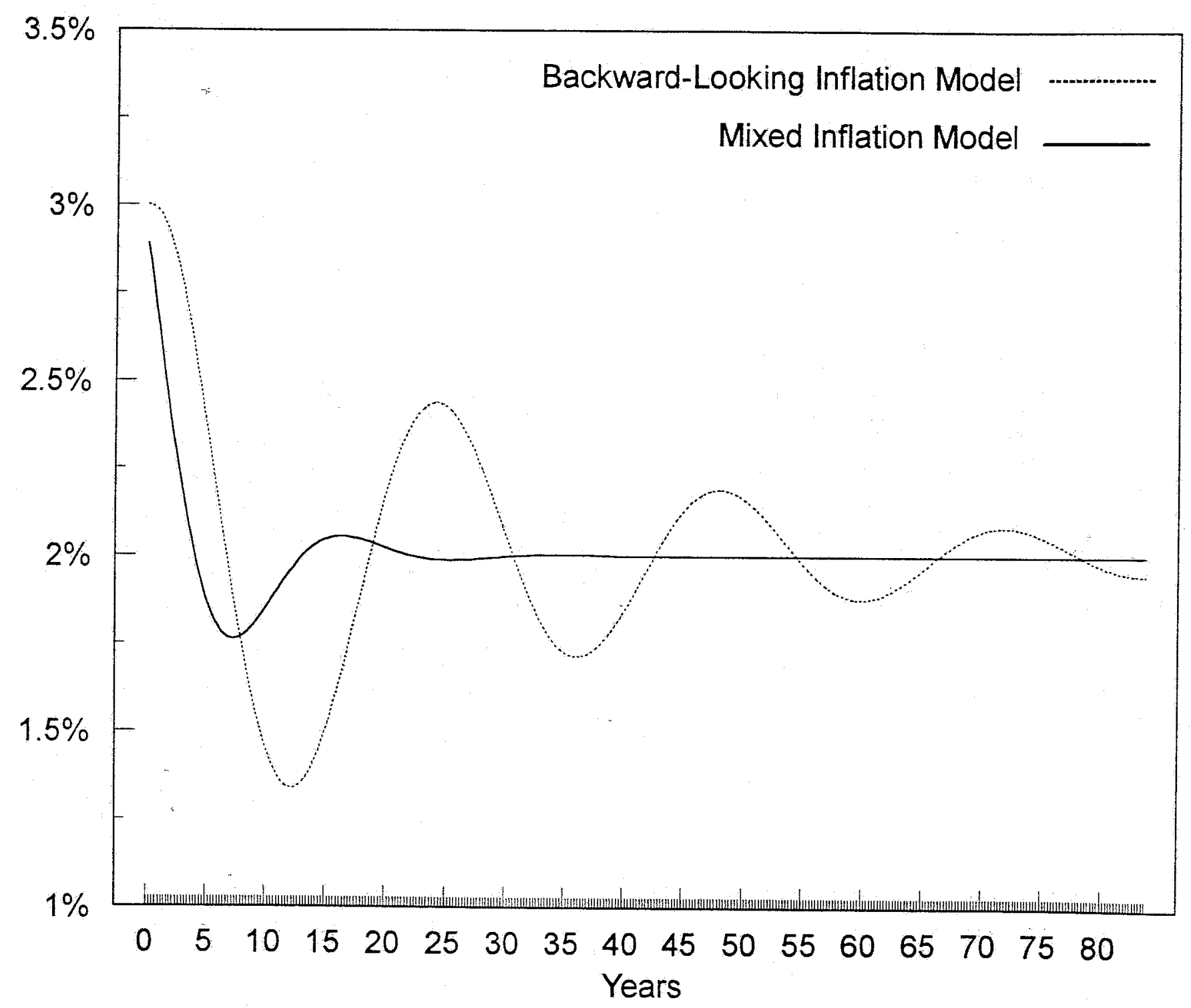


are not enough twenty- to forty-year episodes in U.S. postwar data to rule out such behavior, I think it is a desirable feature of an inflation model that it return to its steady state within a reasonable period.

In essence, the forward-looking component of the inflation specification acts to stabilize the model. It is possible that other model features could perform the same role (see, for example, Fuhrer and Moore 1995c). Thus forward-looking behavior in the inflation specification constitutes a sufficient, but not a necessary, condition to obtain what I consider to be "reasonable" model dynamics in rational expectations models.

\section{Conclusions}

I test the empirical significance of expected future prices in forward-looking contract price specifications like those of Taylor. I find that expectations of future prices are empirically unimportant in explaining price and inflation behavior. However, the dynamics of a model that includes a purely backward-looking inflation specification differ significantly from the dynamics of a model with a forward-looking specification. Thus the choice to include forward-looking behavior in a price specification may in large part hinge upon the use to which the specification is to be put. For pure forecasting purposes, it is unlikely that a forward-looking model will improve upon a backward-looking model. For policy simulations and other longerrun simulations that more explicitly involve the model's dynamics, a mixed backward-looking/forward-looking price specification may provide more reasonable behavior without sacrificing too much on empirical performance. 


\section{References}

[1] Laurence Ball. The Genesis of Inflation and the Costs of Disinflation. Journal of Money Credit and Banking, 23(3, part 2):439-52, August 1991.

[2] Laurence Ball. What Determines the Sacrifice Ratio? In N. Gregory Mankiw, editor, Monetary Policy, chapter 5, pages 155-193. The University of Chicago Press, 1994.

[3] Ben S. Bernanke and Alan S. Blinder. The federal funds rate and the channels of monetary transmission. American Economic Review, 82, No. 4:901-921, 1992.

[4] Flint Brayton and Eileen Mauskopf. The Federal Reserve Board MPS quarterly econometric model of the US economy. Economic Modelling, pages 171-292, July 1985.

[5] Guillermo A. Calvo. Staggered Contracts in a Utility Maximizing Framework. Journal of Monetary Economics, 12(3):383-98, September 1983.

[6] Bankim Chadha, Paul R. Masson, and Guy Meredith. Models of Inflation and the Costs of Disinflation. IMF Staff Papers, 39, No.2:395-431, 1992.

[7] Jeffrey C. Fuhrer and George R. Moore. Monetary Policy Rules and the Indicator Properties of Asset Prices. Journal of Monetary Economics, 29:303-336, April 1992.

[8] Jeffrey C. Fuhrer and George R. Moore. Forward-Looking Behavior and the Stability of a Conventional Monetary Policy Rule. Journal of Money Credit and Banking, 1995. 
[9] Jeffrey C. Fuhrer and George R. Moore. Inflation Persistence. Quarterly Journal of Economics, 110, February 1995.

[10] Jeffrey C. Fuhrer and George R. Moore. Monetary Policy Trade-Offs and the Correlation Between Short Nominal Rates and Real Output. American Economic Review, 85, March 1995.

[11] Edmund S. Phelps. Disinflation without Recession: Adaptive Guideposts and Monetary Policy. Weltwirtschaftiches Archiv, 100(2):239-265, 1978.

[12] Jr. Robert E. Lucas. Econometric testing of the natural rate hypothesis. In Otto Eckstein, editor, The Econometrics of Price Determination Conference. Board of Governors of the Federal Reserve System, 1972.

[13] T. Sargent and N. Wallace. Rational expectations, the optimal monetary instrument and the optimal money supply rule. Journal of Political Economy, 1975.

[14] John B. Taylor. Aggregate Dynamics and Staggered Contracts. Journal of Political Economy, 88(1):1-24, February 1980. 